\title{
The genome sequence of pepper vein yellows virus (family Luteoviridae, genus Polerovirus)
}

\author{
Ritsuko Murakami • Nobuhiko Nakashima • \\ Norihide Hinomoto $\cdot$ Shinji Kawano • \\ Tetsuya Toyosato
}

Received: 18 October 2010/Accepted: 23 February 2011/Published online: 13 March 2011

(C) The Author(s) 2011. This article is published with open access at Springerlink.com

\begin{abstract}
The complete genome of pepper vein yellows virus (PeVYV) was sequenced using random amplification of RNA samples isolated from vector insects (Aphis gossypii) that had been given access to PeVYV-infected plants. The PeVYV genome consisted of 6244 nucleotides and had a genomic organization characteristic of members of the genus Polerovirus. PeVYV had highest amino acid sequence identities in ORF0 to ORF3 (75.9 - 91.9\%) with tobacco vein distorting polerovirus, with which it was only $25.1 \%$ identical in ORF5. These sequence comparisons and previously studied biological properties indicate that PeVYV is a distinctly different virus and belongs to a new species of the genus Polerovirus.
\end{abstract}

\section{Introduction}

Since 1981, bell pepper plants (Capsicum annuиm L. var. grossum Sendt.) showing vein yellowing and leaf roll, symptoms very similar to those of the recently reported pepper yellow leaf curl virus (PYLCV) [3], have been

Nucleotide sequence data reported are available in DDBJ/EMBL/ Genbank database under the accession number AB594828.

R. Murakami $(\bowtie) \cdot$ N. Nakashima $\cdot$ N. Hinomoto

National Institute of Agrobiological Sciences,

Tsukuba, Ibaraki 305-8634, Japan

e-mail: mritsuko@affrc.go.jp

\section{S. Kawano}

Okinawa Prefectural Agricultural Research Center, Itoman, Okinawa 901-0336, Japan

T. Toyosato

Tropical Technology Center Co., Ltd, Uruma,

Okinawa 904-2234, Japan observed every year in Okinawa Prefecture, Japan. A virus resembling a luteovirus was isolated from the plants, and initial studies showed that the virus replicates in phloem tissues and was transmitted by grafting and the aphid vector, Aphis gossypii Glover, in a persistent manner [13]. The virus was named pepper vein yellows virus (PeVYV) [13]. Here, we report the complete genome sequence of PeVYV.

In 2009, infected bell pepper plants showing typical symptoms of PeVYV were again obtained at the same place where the first isolation of PeVYV was done [13] because previously purified virions were unavailable. PeVYV-infected plants were maintained in a greenhouse by continuous aphid transmission to healthy bell pepper plants. Since RT-PCR using several primers for luteoviruses did not amplify cDNAs of PeVYV from infected plants, we first prepared RNA samples from 300 viruliferous A. gossypii, which had been given an acquisition access on the infected plants for two weeks. Then, randomly amplified RT-PCR products (ranging in size from 300 to $800 \mathrm{bp}$ ) were obtained according to the methods of Ryabov [11] and were cloned into pGEM-T Easy Vector (Promega). Inserts of 576 clones were sequenced and assembled. The 293 clones formed two contigs: one contig having 4034 nucleotides (nt) showed $86.0 \%$ sequence identity to nt 224-4257 of tobacco vein distorting virus (TVDV) [10], and the other contig having $93 \mathrm{nt}$ also showed $93.1 \%$ identity to nt $5814-5906$ of TVDV. The $5^{\prime}$ and $3^{\prime}$ terminal sequences were obtained using the $5^{\prime}$ and $3^{\prime}$ RACE systems of Invitrogen, the latter after polyadenylation of RNAs. Sequences between the two contigs were determined using specific primers for RT-PCR. The total length of the assembled sequence obtained from the aphids was $6244 \mathrm{nt}$. To rule out errors in sequence assembly, we sequenced RT-PCR products containing the junction 
regions of the contigs from the PeVYV-infected bell pepper plants. In addition, primers designed to amplify nt 239-1484, 1327-2754, 2524-4268, and 4194-6186 of the assembled sequence gave the expected DNA fragment sizes when RT-PCR was carried out using samples from infected plants, confirming that the assembled sequence represents the PeVYV sequence.

Comparisons of the nucleotide sequence of PeVYV and other fully sequenced viruses showed that nt 1-4252 of PeVYV had highest identity (85.1\%) with nt 1-4261 of TVDV, and nt 4253-4996 of PeVYV had highest identity (77.1\%) with nt $4105-4851$ of cucurbit aphid-borne yellows virus (CABYV). Nucleotides 5018-5808 of PeVYV had $51.8 \%$ identity with nt $5010-5802$ of potato leafroll virus, and nt 5878-5978 of PeVYV were again $88.1 \%$ identical to nt 5815-5915 of TVDV, which are located in the $3^{\prime}$ NCR of TVDV. The sequence of nt 6083-6244 of PeVYV had no similarity to other viruses.
The $5^{\prime}$ NCR of PeVYV was $51 \mathrm{nt}$ long, resembling the NCR of poleroviruses. The $5^{\prime}$ NCR of most poleroviruses is shorter than $100 \mathrm{nt}$, whereas the NCRs of luteoviruses and enamoviruses are longer than $100 \mathrm{nt}$. The $5^{\prime}$-terminal region of the PeVYV sequence, ACAAAA, is identical in many poleroviruses, e.g., beet mild yellowing virus [7], CABYV [6], melon aphid-borne yellows virus [12] and TVDV [10].

The RNA genome of PeVYV contained six major open reading frames (ORFs), resembling those of poleroviruses in arrangement and sequence. Properties of the deduced amino acid sequence of each ORF were as follows: (i) ORF0, encoded by nt 52-801, contains an F-box consensus sequence [9] at nt 217-231; (ii) ORF1, encoded by nt 176-2140, has a serine protease motif at nt 893-1270, and the N-terminus of a genome-linked protein [10] maps to amino acid position 403; (iii) ORF2, encoded by nt 1621-3432, is an RNA-dependent RNA polymerase

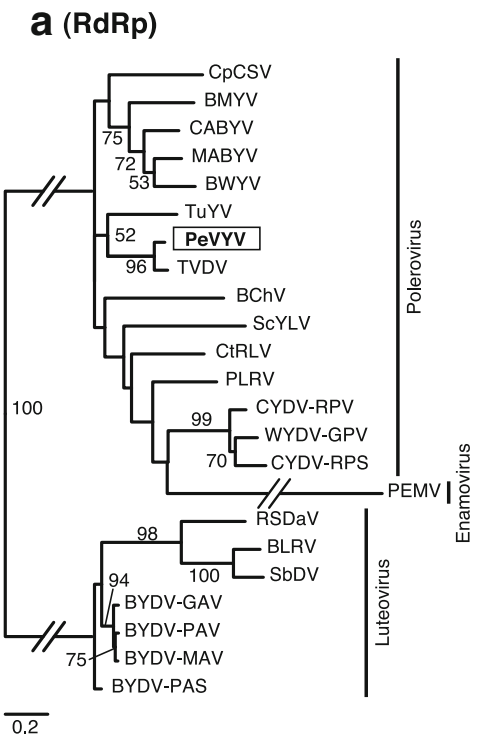

Fig. 1 Relationship of PeVYV to members of the genera Luteovirus, Polerovirus and Enamovirus using amino acid sequences of the RNAdependent RNA polymerase (RdRp, a), the coat protein $(\mathrm{CP}, \mathbf{b})$ and the readthrough domain $(\mathrm{RTD}, \mathbf{c})$. The complete genome sequences of the viruses were obtained from GenBank, and pepper yellow curl virus (PYLCV, accession number HM439608) and pepper yellows virus (PYV, FN600344) were also included in the CP analysis. Amino acid sequences were aligned using MUSCLE [4], and maximumlikelihood phylogenetic trees were constructed with PhyML [8] with the best-fit models of amino acid substitution selected by ProtTest [1], as judged by the Akaike information criterion. The models employed were $\mathrm{LG}+\mathrm{G}+\mathrm{F}$ for $\mathrm{RdRp}$ and $\mathrm{LG}+\mathrm{G}$ for $\mathrm{CP}$ and $\mathrm{RTD}$, respectively. Numbers on branches indicate bootstrap support values for 1,000 replicates, and values less than $50 \%$ are not shown. In panel a, the horizontal lines between luteoviruses and poleroviruses were shortened to one-fifth, and the line between poleroviruses and enamovirus was shortened to one-half. The virus abbreviations and accession numbers are as follows: BYDV-GAV, barley yellow dwarf virus-

\section{C (RTD)}

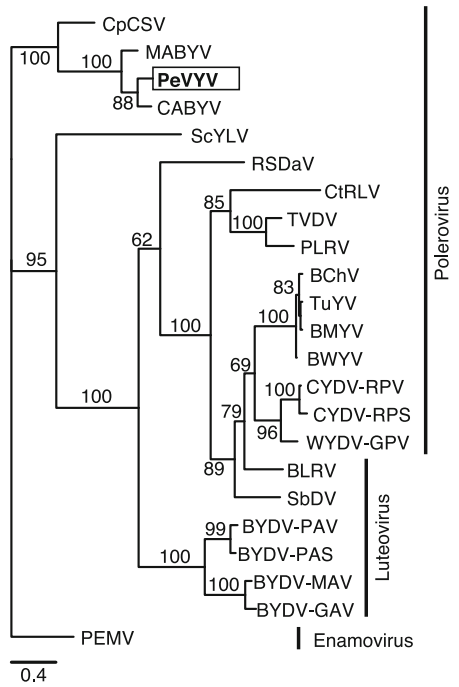

GAV, NC_004666; BYDY-MAV, barley yellow dwarf virus-MAV, NC_003680; BYDV-PAS, barley yellow dwarf virus-PAS, NC_00 2160; BYDY-PAV, barley yellow dwarf virus-PAV, NC_004750; BChV, beet chlorosis virus, NC_002766; BLRV, bean leafroll virus, NC_003369; BMYV, beet mild yellowing virus, NC_003491; BWYV, beet western yellows virus, NC_004756; CABYV, cucurbit aphid-borne yellows virus, NC_003688; CpCSV, chickpea chlorotic stunt virus, NC_008249; CtRLV , carrot red leaf virus, NC_006265; CYDV-RPS, cereal yellow dwarf virus-RPS, NC_002198; CYDVRPV, cereal yellow dwarf virus-RPV, NC_004751; MABYV, melon aphid-borne yellows virus, NC_010809; PEMV, pea enation mosaic virus-1, NC_003629; PLRV, potato leafroll virus, NC_001747; RSDaV, rose spring dwarf-associated virus, NC_010806; SbDV, soybean dwarf virus, NC_003056; ScYLV, sugarcane yellow leaf virus, NC_000874; TuYV, turnip yellows virus, NC_003743; TVDV, tobacco vein distorting virus, NC_010732; WYDV-GPV, wheat yellow dwarf virus-GPV, NC_012931 
(RdRp) and appears to be translated through a -1 frameshift by a shifty heptanucleotide at nt 1654-1660; (iv) ORF3, encoded by nt 3632-4252, is the coat protein (CP); (v) ORF4, encoded by nt 3663-4133, is a movement protein in a distinct +1 reading frame of ORF3; (vi) ORF5, encoded by nt 4253-5842, is a readthrough domain (RTD) of ORF3 and has a proline hinge [6] at nt 4253-4339.

PeVYV had an intergenic NCR of 199 nt between ORF2 and ORF3, similar to other poleroviruses, whereas luteoviruses and enamoviruses have an intergenic NCR of about 100 nt. These characteristics also indicate that PeVYV is a polerovirus.

The $3^{\prime}$ NCR of PeVYV was 402 nt long, making it longer than those of other known poleroviruses but considerably shorter than the $3^{\prime}$ NCR of luteoviruses ( $\left.>600 \mathrm{nt}\right)$. Secondary structure prediction of the $3^{\prime}$ NCR of PeVYV detected 11 stem loops (data not shown). The sequence containing the first and second stem loops, nt 5923-5977, and that containing the third and fourth stem loops, nt 5992-6046, were nearly identical, suggesting that duplication of this sequence segment had occurred in the $3^{\prime}$ NCR of PeVYV, as has been observed for flaviviruses [5].

Phylogenetic trees of the RdRp, CP and RTD sequences of viruses of the family Luteoviridae also supported that PeVYV is a member of the genus Polerovirus (Fig. 1). Analysis of RdRp and CP sequences showed that PeVYV was closely related to TVDV, whereas an RTD analysis suggested that PeVYV was only distantly related to TVDV. Based on amino acid sequence identities for ORFs 0-3, the closest relative of PeVYV was TVDV (75.9-91.9\%), but ORF5 of TVDV has only $25.1 \%$ amino acid identity to that of PeVYV. One of the species demarcation criteria for viruses of the family Luteoviridae is that differences in amino acid sequences of any gene product must be greater than $10 \%$ [2]. In addition, a previous transmission test [13] showed that PeVYV did not infect tobacco plants. These observations indicate that PeVYV belongs to a distinct species in the genus Polerovirus.

Recently, partial genome sequences of polerovirus isolates from pepper have been reported from Israel [3] (PYLCV, accession number HM439608) and from Turkey (pepper yellows virus, PYV, FN600344). The available nt sequence of PYLCV had 93.4\% identity with nt 3815-4252 of PeVYV, and that of PYV was $94.7 \%$ identical to $\mathrm{nt}$ 2613-4242 of PeVYV. The partial ORFs (ORFs 2, 3 and 4) of PYLCV and PYV showed 93-98\% amino acid sequence identity to those of PeVYV. Thus, these two viruses appear to be geographic variants of PeVYV, all of which might form a new polerovirus species.

Open Access This article is distributed under the terms of the Creative Commons Attribution Noncommercial License which permits any noncommercial use, distribution, and reproduction in any medium, provided the original author(s) and source are credited.

\section{References}

1. Abascal F, Zardoya R, Posada D (2005) ProtTest: selection of bestfit models of protein evolution. Bioinformatics 21:2104-2105

2. D'Arcy CJ, Domier LL (2005) Family Luteoviridae. In: Fauquet CM, Mayo MA, Maniloff J, Desselberger U, Ball LA (eds) Virus taxonomy VIII. Elsevier, San Diego, pp 891-900

3. Dombrovsky A, Glanz E, Pearlsman M, Lachman O, Antignus Y (2010) Characterization of Pepper yellow leaf curl virus, a tentative new Polerovirus species causing a yellowing disease of pepper. Phytoparasitica 38:477-486

4. Edger RC (2004) MUSCLE: multiple sequence alignment with high accuracy and high throughput. Nucleic Acids Res 32:1792-1797

5. Gritsun TS, Gould EA (2007) Origin and evolution of 3'UTR of flaviviruses: long direct repeats as a basis for the formation of secondary structures and their significance for virus transmission. Adv Virus Res 69:203-248

6. Guilley H, Wipf-Scheibel C, Richards K, Lecoq H, Jonard G (1994) Nucleotide sequence of cucurbit aphid-borne yellows luteovirus. Virology 202:1012-1017

7. Guilley H, Richards KE, Jonard G (1995) Nucleotide sequence of beet mild yellowing virus RNA. Arch Virol 140:1109-1118

8. Guindon S, Gascuel O (2003) A simple, fast, and accurate algorithm to estimate large phylogenies by maximum likelihood. Syst Biol 52:696-704

9. Kozlowska-Makulska A, Guilley H, Szyndel MS, Beuve M, Lemaire O, Herrbach E, Bouzoubaa S (2010) P0 proteins of European beet-infecting poleroviruses display variable RNA silencing suppression activity. J Gen Virol 91:1082-1091

10. Mo X, Chen Z, Chen J (2010) Complete nucleotide sequence and genome organization of a Chinese isolate of Tobacco vein distorting virus. Virus Genes 41:425-431

11. Ryabov EV (2007) A novel virus isolated from the aphid Brevicoryne brassicae with similarity to Hymenoptera picorna-like viruses. J Gen Virol 88:2590-2595

12. Xiang H, Shang Q, Han C, Li D, Yu J (2008) Complete sequence analysis reveals two distinct poleroviruses infecting cucurbits in China. Arch Virol 153:1155-1160

13. Yonaha T, Toyosato T, Kawano S, Osaki T (1995) Pepper vein yellows virus, a novel luteovirus from bell pepper plants in Japan. Ann Phytopathol Soc Jpn 61:178-184 